\title{
Research on Application-oriented Innovation and entrepreneurship Training Platform Construction Based on TRIZ Theory
}

\author{
Jiangyan Ke \\ College of Mechanical and Energy Engineering, Jimei University, Xiamen 361021, Fujian Province, China
}

Keywords: TRIZ theory; applied innovative and entrepreneurial talent training

\begin{abstract}
In today's world integration, it is hoped to develop the country better today, let the country continue to make progress in the world, and continue to innovate. Innovation is the soul of a nation's progress. If no innovation is made, the country will lag behind. Especially for China, at the present stage, it is necessary to cultivate talents who are good at innovation, so as to ensure that the country's economic construction is getting better and better. As the most important institution in our country, colleges and universities are required to cultivate talents' innovative ability to a large extent. Therefore, it is imminent to establish an innovative talent platform suitable for colleges and universities. The main purpose of this paper is to apply the TRIZ theory as the main innovation theory to the training of innovative talents in colleges and universities, and to develop and study the innovative talent platform.
\end{abstract}

\section{Introduction}

With the advent of the era of knowledge economy, in order to ensure the development of the country in the present era, it is necessary to ensure the development of innovative talents. With the increasing importance of innovative talents, all countries in the world have set off a deepening reform of education and the upsurge of cultivating innovative talents. In particular, the "innovative talents" in China has become the most important point in the process of learning and training in universities. In order to cultivate more innovative talents, the related personnel training platform has also been put on the agenda. There are many problems in the way and method of innovation training in foreign countries, and there are many problems in our country. The loopholes in the traditional education mode need a little complement. Although the colleges and universities in our country begin to carry out various kinds of innovative competitions at the present stage, the students are involved. Limitation does not give more students opportunities to learn and exercise.

\section{Training Mode of Innovative Talents}

With the development of economy and society, in order to ensure the better development of the country in the present economic environment, what must be done is to be invincible in all kinds of competition. In the twenty-first Century, the development of our society is becoming more and more rapid, and the competition is becoming more and more. The competition, the competition of science and technology, the competition of politics, the competition of military and the competition of culture are all telling us that if we do not improve the comprehensive national strength, we will be eliminated, and the competition is in the final analysis. It is the competition for talents, especially for the competition of innovative talents. For this purpose, it is necessary to cultivate innovative talents in order to ensure that our country can go forward in the wave of world competition.

In order to cultivate innovative talents, what must be done is to cultivate the creative quality of the talent itself, and the so-called innovation quality itself mainly includes two factors, namely, the quality factors of intelligence and the quality factors of non intelligence. In the process of cultivating intellectual quality factors, the main training is the innovator's own memory, absorptive capacity, imagination, observation and practical ability. But what innovation needs to rely on is not only intellectual factors, but also the non intellectual factors of the creator, including diligence, self-confidence, curiosity, questioning, enthusiasm, courage, interest and so on. But we want to 
better build a training platform for innovative talents, which is mainly the intellectual factors of innovative talents. This paper mainly discusses how to cultivate the intellectual quality factors in the construction of the platform construction of the applied innovation and entrepreneurial talent training based on TRIZ theory. The so-called absorptive capacity mainly includes the learning ability of innovators and the ability to collect information. As a innovator, if it does not have a strong ability to learn, then in the process of engaging in creative activities, it will feel that the applied knowledge is relative to the obsolescence, the chosen method is relative to the outdated, and the ideas and means are relative to the single. For this purpose, we want to cultivate an innovator's own innovative accomplishment. The first thing to strengthen is the innovator's own learning ability, especially the self learning ability of the innovator. The innovation can not rely too much on the book, but to observe and think about all kinds of things in the daily life. And solve problems, so that we can achieve real innovation. In order to effectively improve the innovator's self-study ability, it can be carried out from the following three aspects: stubbornness and diligence. In the process of innovation, once the difficult problems are not abandoned and do not give up the effort, they do not cry out and do not cry hard in the process of learning. In the process of innovation, in the process of innovation, we should actively ask, refuse to understand, and in the daily life of the life of all kinds of things to continue to think; scientific reading, reading is the innovator itself must do things, reading can be improved The new person's own eyes can also help the innovators to better open up their thinking. In the course of reading, we should read scientifically, and read the reading with the cross reading and the intensive reading. The ability to collect information mainly refers to the ability and ability of the innovator to collect information and information, to discover information and to analyze and use it effectively, to improve the efficiency of the innovator's ability to directly connect information collection.

People often say that memory is good or bad, to a certain extent, determines the good or bad of a person's learning. In the process of creation, memory is also a very important ability. He is an instinctive response to what the human brain is and has already experienced, and also a creative person who works and studies. One of the basic conditions that can not be lacking in the process of creation. In the process of creation, we rely on memory to help us call past experience and knowledge. Therefore, we must cultivate the memory ability of the innovator. Using the scientific memory method can make the memory effect twice the result. In the condition of improving the function of the brain, it can effectively improve the efficiency of memory and excavate the big human. The potential ability in the brain. In the process of practical application, the common memory methods include: the key memory method, the system memory method, the system memory method, the associative memory method, the memory memory method, the image memory method, the practice memory method and so on.

Imagination can also be called the ability of human imagination. This ability is based on the memory of human beings. In the process of actual work and life, it describes the different scenes constructed by thinking activity or the rediscovery of some objective things, or the conception of new functions. The imagination is very important for the innovator. Without imagination, there is no way to innovate, so it is necessary to cultivate imagination. It can be developed by the following ways: the accumulation of knowledge and the experience of life and work. These knowledge and experience can help. To help innovators build a realized component in the process of daily thinking; constantly strengthen curiosity, curiosity is the foundation of imagination, and many new theoretical origins are curiosity; fostering the passion for creation is not to be treated seriously if there is no passion for a thing.

Unlike other abilities, the ability to observe varies widely. This is a purposeful and organized perception and is comprehensive. In the application of observation ability, innovators need to understand all the characteristics of things in a comprehensive and correct way. For the innovator to cultivate its own observation ability can make it better understand a thing, but the ability of observation is not an independent existence, it needs to develop the innovator's thinking, knowledge, experience accumulation and so on. 


\section{Set up the Training Platform for Innovative and Entrepreneurial Talents}

In the process of building up the training platform for innovative and entrepreneurial talents, the theory is based on the theory of TRIZ. The purpose of it is to cultivate and discover innovative talents. In this platform, the main purpose of this platform is to help the talents in Colleges and universities to learn innovative thinking and to cultivate students' innovative ability. Students are interested in innovation and continue to improve their interests. In this platform, the TRIZ theory is used as an innovation theory. Through the application of this theory, the user's desire for innovation is trained and encouraged. At the same time, the user's ability to expand and innovate is developed so that users can find more innovative points in the process of using the platform, and choose a reasonable innovation way to achieve better achievement. The purpose of innovation, after all, in the process of innovation, we must take into account the possibility of practical application, to this end the rational innovation is the real needs of the national development of innovative talents.

In the process of learning TRIZ theory, because of its own theoretical knowledge point relative to more, and there is no concrete general situation, it is not convenient for users to learn in the process of practical learning. In the process of establishing the platform, the first thing to do is to sum up and summarize the complicated knowledge points in the TRIZ theory according to their own process, and divide the TRIZ theory into the following three sections: the basic theory, the tool layout, the tool page based on knowledge, which are convenient for the users to learn. It allows users to understand and accept more quickly. In addition, when the TRIZ theory is applied, the standard solution, innovation algorithm and so on are relative to more complex computing tools. In the process of practical application, it is not necessary for the general innovation problem. This requires the manager of the platform, which should solve the standard solution to the actual situation. The application of the method and the innovation algorithm is simplified and improved, so that innovators can learn and use more comfortably.

At the present stage, the biggest problem in the process of the development of innovative talents in China is to find out what is the core point of the bottleneck in each innovation, which leads to the innovation of innovative talents in the actual work, but how to make better use of the existing points at the present stage. An analysis of tools or knowledge based tools to solve the problem of innovation is a problem that everyone will encounter. In order to find the core point to solve this problem, a problem analysis method is established by using the platform, that is to say, edit the cause and effect model in the platform, and use the causality model to find this question directly. The core of the problem is to find the most reasonable solutions and solutions based on the problem, so that the innovators can quickly find out the problems, solve the problems and make better innovative development.

For any innovative talent, after applying the platform of TRIZ theory, it will work hard to learn innovation theory and the latest method of application innovation. In the process of continuous learning, users can feel and discover their own innovation ability, but it is very important to test how to improve the innovation ability. One of the questions is, after all, the best way to test truth, to learn and to learn is to be good or bad. After the emergence of the innovators, the platform can be used to evaluate the results of the innovation. In this way, the innovators can directly feel their ability to innovate. At the same time, the innovators of the platform can also modify the inappropriate places in their own results. Improve their own innovative ability and innovative quality. In the process of cultivating innovative talents, the main use of the platform to evaluate the results is 48 different engineering parameters. These parameters can be defined and analyzed for the useful function (Useful Function) and the harmful function (Harmful Function) in the results. It is Delphy Fa's right to use this method to achieve the ideal of evaluating the achievement of innovation, and the main advantages of this way are:

The use of engineering parameters to evaluate the innovation results can effectively and directly avoid the subjective differences and errors in the process of human evaluation, and the use of different and multiple engineering parameters to evaluate the results of innovation can maximize its own function value.

For any technology to improve technology, it is necessary to solve the problems that existed in 
the past, that is to say, to overcome the contradictions and then to realize their own evolution, and the use of this evaluation method can effectively solve the problems existing in the innovation results, and accurately analyze the innovation at the present stage. The relationship between evolution and ideality can directly help creators to correct problems and achieve better innovation results.

\section{Conclusion}

According to this article, we know that in order to build an innovative and continuous development country, we must develop the innovation education vigorously, and apply the TRIZ theory to optimize and develop the training platform of innovative and entrepreneurial talents, to ensure that it can be updated and updated horizontally, so as to ensure the application of College students. . At the same time, we can also optimize the platform independently according to the characteristics of different colleges and universities, take the development of the students as the base, and provide the students with the platform of innovation and development to the maximum limit. In this way, the innovative talents in our country can produce continuous production, so as to ensure that the world knowledge economy development is not eliminated today and more. Stable development of social and economic construction.

\section{Acknowledgment}

Fund Project: Education and research projects for young teachers in Fujian Provincial Education Hall (2017 JAT170321)

\section{References}

[1] Wang X, Nannan L I, Cui W. Enhance College Students Innovation and Entrepreneurship Capability Based on TRIZ [J]. Pioneering with Science \& Technology Monthly, 2018.

[2] Wang L. Research on Innovation and Entrepreneurship Education for College Students Based on the TRIZ Theory [J]. Journal of Heihe University, 2017.

[3] Yan X, Zhang Z. Discussion on Promotion Model of the TRIZ Theory with the Background of qMass Entrepreneurship and Innovationq[C]// International Conference on Education Science and Economic Management. 2017.

[4] Chen C, Management S O. Research on TRIZ Knowledge Demand Characteristics of College and University Students_-Taking Engineering Schools of Fujian University of Technology as Examples[J]. Innovation Science \& Technology, 2017.

[5] Mao G, Wang S, Teng Q, et al. The sustainable future of hydropower: A critical analysis of cooling units via the Theory of Inventive Problem Solving and life cycle assessment methods [J]. Journal of Cleaner Production, 2016, 142.

[6] Hooge S, Agogué M. Improving radical innovation methods for strategy making - Learning from practitioners' evaluations of practical guidelines for C-K tools [J]. Post-Print, 2017. 